\title{
Clinical and laboratory characteristics of neonatal hypocalcemia
}

\author{
Won Im Cho, MD', \\ Hyeoh Won Yu, MD', \\ Hye Rim Chung, MD, PhD², \\ Choong Ho Shin, MD, PhD', \\ Sei Won Yang, MD, PhD', \\ Chang Won Choi, MD, PhD², \\ Beyong II Kim, MD, PhD²

\section{${ }^{1}$ Department of Pediatrics, Seoul National University Children's Hospital, Seoul, ${ }^{2}$ Department of Pediatrics, Seoul National University Bundang Hospital, Seongnam, Korea}

Purpose: To describe the clinical characteristics of full-term neonates with hypocalcemia and to suggest factors associated with neonatal hypocalcemia Methods: The medical records of full-term neonates with hypocalcemia were reviewed. Hypocalcemia was defined as an ionized calcium (iCa) concentration of $<4$ $\mathrm{mg} / \mathrm{dL}$. Parathyroid hormone (PTH) insufficiency was defined as a serum PTH level of $<60 \mathrm{pg} / \mathrm{mL}$ or a serum phosphorus level higher than the serum calcium level in the presence of hypocalcemia.

Results: Fifty-three neonates were enrolled. The median age at diagnosis of hypocalcemia was 3 days. In all the neonates, formula feeding predominance was observed. Thirty-eight neonates (69.8\%) were compatible with PTH insufficiency. The number of formula-fed neonates was significantly higher than that of breastfed patients among neonates with PTH insufficiency $(P=0.017)$. Intact PTH was negatively correlated with serum phosphorus levels. Twelve out of 14 neonates (85.7\%) had 25-hydroxy vitamin D (25OHD) levels $<20 \mathrm{ng} / \mathrm{mL}$ and 9 neonates (64.3\%) had $25 \mathrm{OHD}$ levels $<10 \mathrm{ng} / \mathrm{mL}$. Twenty-one neonates had hypocalcemic tetany. The serum calcium and iCa concentrations of neonates with tetany were 4.2-8.3 $\mathrm{mg} / \mathrm{dL}$ and $1.85-3.88 \mathrm{mg} / \mathrm{dL}$, respectively. Three neonates showed symptomatic hypocalcemia with calcium levels over $7.5 \mathrm{mg} / \mathrm{dL}$. Among the 16 neonates who underwent electroencephalography (EEG), 12 had abnormalities, which normalized after 1-2 months.

Conclusion: Formula milk feeding, PTH insufficiency and low serum vitamin D concentration are associated with the development of neonatal hypocalcemia. Symptoms such as tetany and QT interval prolongation can develop in relatively mild hypocalcemia. Moreover, transient neonatal hypocalcemia can cause transient EEG abnormalities.

Keywords: Hypocalcemia, Newborn infant, Parathyroid hormone, Tetany
Received: 2 June, 2015

Revised: 16 June, 2015

Accepted: 22 June, 2015

Address for correspondence: Hye Rim Chung, MD, PhD Division of Endocrinology and Metabolism, Department of Pediatrics, Seoul National University Bundang Hospital, 82 Gumiro 173beon-gil, Bundang-gu, Seongnam 463-707, Korea Tel: +82-31-787-7292

Fax: +82-31-787-4054

E-mail: chyerim@hanmail.net

\section{Introduction}

The calcium present in serum is important for maintaining the homeostasis of the body, the functioning of cellular processes, cellular membrane stability, muscle contraction, and nerve conduction $^{1)}$. Parathyroid hormone (PTH), vitamin D, and calcitonin are essential hormones for the balance of serum calcium levels. Serum calcium levels are also affected by calcium and phosphate intake and serum magnesium $(\mathrm{Mg})$ levels ${ }^{2}$.

Although calcium is transferred actively from mother to fetus during the third trimester of gestation, the abrupt cessation of placental transfer of calcium occurring after birth is regarded as a major factor in neonatal hypocalcemia ${ }^{3)}$. In addition, inappropriate PTH response to hypocalcemia, vitamin D insufficiency and increased calcitonin secretion also take part in hypocalcemia during the early neonatal period ${ }^{2}$.

Although neonatal hypocalcemia can be a potentially life-threatening condition, laboratory 
hypocalcemia is often asymptomatic and transient. Moreover, prevalence varies by gestational age (GA) and perinatal disea$\mathrm{se}^{4,5)}$. For these reasons, the definition of hypocalcemia in the neonatal population is not well established, and the therapeutic cutoff level of low serum calcium is controversial. In addition, the associated factors affecting the parathyroid axis in neonates have not been fully verified ${ }^{6,7)}$.

The purpose of this study was to describe the clinical characteristics of hypocalcemia and to suggest factors associated with the development of hypocalcemia in term neonates.

\section{Materials and methods}

We retrospectively reviewed the medical records of fullterm neonates with transient neonatal hypocalcemia at the Seoul National University Bundang Hospital from June 2006 to March 2014. We searched for full-term neonates (GA $\geq 37$ weeks) who had been diagnosed with hypocalcemia using the keywords "hypocalcemia", "vitamin D deficiency", and "hypoparathyroidism" in the Clinical Data Warehouse of the institution. Among 183 neonates who met the diagnostic keywords, 127 preterm neonates and 3 neonates with insufficient information were excluded. Finally, 53 neonates were enrolled. Clinical data were retrospectively analyzed in terms of GA, birth weight, feeding type, and age at diagnosis of hypocalcemia. Laboratory findings at the diagnosis of hypocalcemia were also reviewed. All the neonates were diagnosed with hypocalcemia within 4 weeks after birth. Nineteen out of the 53 neonate patients initially presented with tetany. The remaining 34 infants were admitted and tested for serum calcium level because of newborn transient tachypnea $(n=9)$, perinatal asphyxia $(n=7)$, maternal history of diabetes $(n=7)$, jaundice $(n=3)$, gastrointestinal problems $(n=3)$, $22 \mathrm{q}$ microdeletion syndrome $(\mathrm{n}=1)$, or other reasons $(\mathrm{n}=4)$.

Transient neonatal hypocalcemia (TNH) was defined as hypocalcemia detected within 28 days of birth and cured in response to treatment of limited duration. We defined hypocalcemia as serum ionized calcium (iCa) concentration of less than 4.00 $\mathrm{mg} / \mathrm{dL}(1.0 \mathrm{mmol} / \mathrm{L})^{4)}$. PTH insufficiency was defined as a condition with a level of serum PTH less than $60 \mathrm{pg} / \mathrm{mL}$ or serum phosphorus level higher than serum calcium level in the presence of hypocalcemia. Miscellaneous hypocalcemia was defined as TNH unrelated to PTH insufficiency. Early-onset hypocalcemia was defined as hypocalcemia detected within 3 days after birth and late-onset hypocalcemia as a diagnosis of hypocalcemia made after 3 days. To determine the effects of birth weight, the enrolled neonates were grouped as small for

Table 1. Characteristics of full-term neonates with transient neonatal hypocalcemia

\begin{tabular}{|c|c|c|c|}
\hline Characteristic & Total $(n=53)$ & PTH insufficiency $(n=37)$ & Miscellaneous $(n=16)$ \\
\hline \multicolumn{4}{|l|}{ Gender } \\
\hline Male & $35(66.0)$ & $25(67.6)$ & $10(62.5)$ \\
\hline Female & $18(34.0)$ & $12(32.4)$ & $6(37.5)$ \\
\hline \multicolumn{4}{|l|}{ Birth weight for gestational age } \\
\hline SGA & $7(13.2)$ & $4(10.8)$ & $3(18.7)$ \\
\hline AGA & $40(75.5)$ & $29(78.4)$ & $11(68.8)$ \\
\hline LGA & $6(11.3)$ & $4(10.8)$ & $2(12.5)$ \\
\hline \multicolumn{4}{|l|}{ Feeding type ${ }^{a)}$} \\
\hline Formula milk feeding & $37(69.8)$ & $29(78.4)$ & $8(50)$ \\
\hline Breast milk feeding & $7(13.2)$ & $2(5.4)$ & $5(31.3)$ \\
\hline Mixed feeding & $4(7.5)$ & $4(10.8)$ & $0(0)$ \\
\hline NPO & $5(9.5)$ & $2(5.4)$ & $3(16.7)$ \\
\hline \multicolumn{4}{|l|}{ Season of birth ${ }^{\text {b) }}$} \\
\hline Spring & $14(26.4)$ & $9(24.3)$ & $5(31.2)$ \\
\hline Summer & $9(17.0)$ & $6(16.3)$ & $3(18.8)$ \\
\hline Fall & $15(28.3)$ & $11(29.7)$ & $4(25.0)$ \\
\hline Winter & $15(28.3)$ & $11(29.7)$ & $4(25.0)$ \\
\hline Gastrointestinal problem & $5(9.4)$ & $2(5.4)$ & $3(18.8)$ \\
\hline Maternal gestational diabetes & $7(13.2)$ & $4(10.8)$ & $3(18.8)$ \\
\hline DiGeorge syndrome & $1(1.9)$ & $1(2.7)$ & $0(0)$ \\
\hline Perinatal asphyxia & $7(13.2)$ & $1(2.7)$ & $6(37.5)$ \\
\hline $250 \mathrm{OH}$ level $<20 \mathrm{ng} / \mathrm{mL}$ & $12 / 14(85.7)$ & 9/11 (81.8) & $3 / 3(100)$ \\
\hline $250 \mathrm{OHD}$ level $<10 \mathrm{ng} / \mathrm{mL}$ & $9 / 14(64.3)$ & $7 / 11(63.6)$ & $2 / 3(66.7)$ \\
\hline Early vs. late onset hypocalcemia & 29 (54.7) vs. 24 (45.3) & 17 (45.9) vs. $20(54.1)$ & 12 (75) vs. 4 (25) \\
\hline
\end{tabular}


GA, appropriate for GA, and large for GA according to birth weights of $<10$ th, 10th-90th, and $>90$ th percentile for GA, respectively. A corrected QT interval (QTc) prolongation on an electrocardiogram (EKG) was defined as a QTc over 0.44 seconds.

Data such as GA, birth weight, age at detection of hypocalcemia, total serum calcium, iCa level, serum phosphorus, $\mathrm{Mg}$, intact PTH, and 25-hydroxy vitamin D (25OHD) at diagnosis of hypocalcemia were presented as median and range. The chi-square test or Fisher exact test was used to determine the relationship between PTH insufficiency and gender, weight for GA, feeding type, and season of birth. The MannWhitney $U$-test was used for comparison of clinical parameters between neonates with PTH insufficiency and miscellaneous hypocalcemia and between neonates with hypocalcemic tetany and asymptomatic hypocalcemia. The Spearman correlation test was performed to show the association between serum PTH, 25OHD, phosphorus, alkaline phosphatase, $\mathrm{Mg}$, creatinine levels and both total calcium and iCa. The Spearman correlation test was also used to evaluate calcium and QTc prolongation on EKG during hypocalcemia. $P$-values less than 0.05 were considered statistically significant, and $P$-values between 0.05 and 0.1 were considered borderline significant. All the calculations were performed in IBM SPSS Statistics ver. 21.0 (IBM Co., Armonk, NY, USA).

This study was approved by the Institutional Review Board of Seoul National University Bundang Hospital (IRB No. B-1407/260-107).

\section{Results}

A total of 53 neonates were enrolled. The median age of detection of hypocalcemia was 3 days (range, 2-14 days). In all the neonates, serum calcium levels were normalized within 3 months. The clinical characteristics of the enrolled neonates are described in Table 1. Males and formula feeding predominance were

Table 2. Laboratory profile at diagnosis of hypocalcemia

\begin{tabular}{lcc}
\hline Variable & No. of subjects & Median (range) \\
\hline Calcium $(\mathrm{mg} / \mathrm{dL})$, total & 53 & $6.7(4.2-8.6)$ \\
Calcium $(\mathrm{mg} / \mathrm{dL})$, ionized & 53 & $3.52(1.84-3.96)$ \\
Phosphorus $(\mathrm{mg} / \mathrm{dL})$ & 53 & $7.8(3.8-12.4)$ \\
Magnesium $(\mathrm{mEg} / \mathrm{L})$ & 34 & $1.8(0.8-2.3)$ \\
Intact PTH $(\mathrm{pg} / \mathrm{mL})$ & 31 & $45.6(10.0-181.0)$ \\
25-hydroxy vitamin D $(\mathrm{ng} / \mathrm{mL})$ & 14 & $8.15(4.30-83.20)$ \\
\hline PTH
\end{tabular}

PTH, parathyroid hormone. observed. Twenty-nine neonates out of 53 were diagnosed with early-onset hypocalcemia and 24 with late-onset hypocalcemia. Thirty-seven neonates (69.8\%) were compatible with PTH insufficiency. The number of infants with exclusive formula milk feeding was significantly higher than that of infants with exclusive breast feeding among the neonates with PTH insufficiency ( $P=0.017)$.

Twelve out of 14 neonates $(85.7 \%)$ who were checked for serum vitamin D levels displayed 25OHD levels $<20 \mathrm{ng} / \mathrm{mL}$ and 9 neonates $(64.3 \%$ ) had 25OHD levels $<10 \mathrm{ng} / \mathrm{mL}$ (Table 1 ). The median total calcium level of these 9 neonates was $6.3 \mathrm{mg} /$ $\mathrm{dL}$ (range, $4.4-7.8 \mathrm{mg} / \mathrm{dL}$ ) and the median phosphorus level was $9.4 \mathrm{mg} / \mathrm{dL}$ (range, $7.2-12.4 \mathrm{mg} / \mathrm{dL}$ ). The median intact PTH level was $49 \mathrm{pg} / \mathrm{mL}$ (range, 10-66 pg/mL). Eight of them had late onset neonatal hypocalcemia. Seven out of these 9 neonates were compatible with PTH insufficiency. Seven neonates were on absolute formula feeding, and 2 were on mixed feeding (data not shown in table).

The medians and ranges of serum total calcium, iCa, Mg, intact PTH, and 25OHD are described in Table 2. Twenty-two out of 31 neonates $(71.0 \%)$ who were tested serum intact PTH showed levels of $<60 \mathrm{pg} / \mathrm{mL}$. Only 2 out of 34 neonates who were tested for serum $\mathrm{Mg}$ showed levels of $<1.5 \mathrm{mg} / \mathrm{dL}$.

The iCa level positively correlated with intact PTH and $\operatorname{Mg}(P=0.001$ and $P=0.010)$ and negatively correlated with phosphorus and alkaline phosphatase levels $(P<0.001$ and $P=0.045$ ) (Table 3 ). The correlation between vitamin $\mathrm{D}$ levels and serum calcium was not statistically significant. Intact PTH was positively correlated with $\mathrm{Mg}$ levels $(r=0.486, P=0.012)$ and negatively correlated with phosphorus levels $(r=-0.529, P=0.003)$ (data not shown in table).

Nineteen neonates initially presented with tetany and 2 presented with tetany during hospital stays. The median age of tetany presentation was 6 days after birth. The range of $\mathrm{iCa}$ concentrations in neonates with tetany was $1.85-3.88 \mathrm{mg} / \mathrm{dL}$ (Table 4). Three neonates showed tetany with calcium levels of more than $7.5 \mathrm{mg} / \mathrm{dL}$. The serum calcium levels of these neonates were $7.5 \mathrm{mg} / \mathrm{dL}, 7.8 \mathrm{mg} / \mathrm{dL}$, and $8.3 \mathrm{mg} / \mathrm{dL}$. Two of the 3 neonates developed hypocalcemic tetany at 3 days after birth, and one developed it at 6 days after birth. All 3 of the neonates were fed with formula. Among the 16 neonates who underwent electroencephalography (EEG), 12 had abnormal EEG findings, which normalized after 1-2 months.

Of the 9 neonates who underwent EKG, 5 showed QTc prolongation. Serum iCa levels tended to be lower in neonates with prolonged QTc than in neonates with normal QTc (1.85-3.53

Table 3. Correlation between ionized calcium and total calcium concentration in serum and other parameters

\begin{tabular}{lcccrcr}
\hline Calcium & Intact PTH & $P$ & Mg & ALP & $25 \mathrm{OHD}$ & \multicolumn{1}{c}{ Cr } \\
\hline Ionized calcium & 0.601 & -0.580 & 0.438 & -0.288 & -0.077 & 0.127 \\
P-value & 0.001 & $<0.001$ & 0.010 & 0.045 & 0.794 & 0.366 \\
Total calcium & 0.289 & -0.382 & 0.496 & -0.347 & 0.200 & 0.138 \\
$P$-value & 0.129 & 0.005 & 0.003 & 0.015 & 0.492 & 0.324 \\
\hline
\end{tabular}

P, phosphorus; Mg, magnesium; ALP, alkaline phosphatase; 25OHD, 25-hydroxy vitamin D; Cr, creatinine. 
Table 4. Comparison with clinical characteristics according to the presence of hypocalcemeia

\begin{tabular}{|c|c|c|c|}
\hline \multirow{2}{*}{ Variable } & \multicolumn{2}{|c|}{ Hypocalcemic tetany } & \multirow{2}{*}{$P$-value } \\
\hline & Presence $(n=21)$ & Absence $(n=32)$ & \\
\hline $\mathrm{GA}(w k)$ & $39^{+4}\left(37^{+0}-41^{+1}\right)$ & $38^{+3}\left(37^{+0}-41^{+1}\right)$ & 0.018 \\
\hline Birthweight (g) & $3,340(2,775-4,050)$ & $3,190(1,910-4,260)$ & 0.217 \\
\hline Gender, male:female & $16: 5$ & 19:13 & 0.247 \\
\hline Age of detection (day) & $6(2-12)$ & $3(2-12)$ & 0.005 \\
\hline Early-onset vs. late-onset & $6: 15$ & $23: 9$ & \\
\hline Calcium (mg/dL), total & $6.2(4.2-8.3)$ & $6.9(5.9-8.6)$ & 0.049 \\
\hline Calcium (mg/dL), ionized & $3.10(1.85-3.88)$ & $3.64(2.36-3.97)$ & 0.033 \\
\hline PTH insufficiency, n (\%) & $20(95.2)$ & $17(53.1)$ & 0.002 \\
\hline
\end{tabular}

Values are presented as median (range) unless otherwise indicated.

GA, gestational age; PTH, parathyroid hormone.

$\mathrm{mg} / \mathrm{dL}$ vs. $2.46-3.76 \mathrm{mg} / \mathrm{dL})$. One neonate in the early detection group was hospitalized because of newborn transient tachypnea, and two neonates visited the emergency room because of seizures.

The median duration of correcting neonatal hypocalcemia was 7 days (range, 0-90 days). The median duration of treatment was significantly longer in neonates with tetany than in those without tetany ( 30 days vs. 4 days, $P=0.043$ ).

\section{Discussion}

In our study, formula feeding predominance was observed, and the number of infants with formula milk feeding was significantly higher than that of infants with breast feeding among the neonates with PTH insufficiency. In addition, intact PTH was negatively correlated with serum phosphorus levels.

The association of formula feeding with neonatal hypocalcemia has been reported in previous studies ${ }^{8,9)}$. Formula-fed infants receive more calcium than breast-fed infants because formula contains about double the calcium of breast milk. However, fractional calcium absorption is lower in formula-fed infants ${ }^{10)}$. Previously, the suggested calcium absorption efficiency was approximately $60 \%$ from human milk and approximately $40 \%$ from infant formula during the first four months of life ${ }^{11,12)}$ Although the relatively poor bioavailability of calcium in cow's milk formula has been suggested, a recent review showed relatively small differences in calcium absorption efficiency between human milk and cow's milk formulas ${ }^{13)}$. Cow's milk formula contains more phosphorus than human breast milk; the average calcium:phosphorus molar ratio of human milk is 1.3:1 at 1 week postpartum and 1.4:1 at 4 weeks postpartum, whereas that of cows' milk is $1.0: 1^{14)}$. A previous review article reported that excess phosphorus intake can disturb the absorption of calcium associated with late onset neonatal hypocalcemia ${ }^{8)}$. Intact PTH levels were induced relatively highly in formula fed infants with phosphorus load in another study ${ }^{9}$. However, in this study intact PTH was negatively correlated with serum phosphorus levels. It was speculated that the excretion of phosphorus was inadequate because PTH secretion was insufficient although the level of phosphorus in blood continued to increase with cow's milk formula feeding. The high incidence of neonatal hypocalcemia in formula-fed neonates may be due to both relatively poor gastrointestinal absorption efficacy of calcium in formula and inadequate phosphorus excretion with insufficient PTH secretion. However, there are many confounders associated with phosphorus excretion; therefore, further studies are needed.

Serum iCa levels were positively correlated with intact PTH levels in our study. The relationship between iCa and intact PTH levels has not been consistent in previous studies ${ }^{4,15)}$. PTH increases in response to low serum calcium concentration, and serum calcium levels increase in response to the action of PTH. Moreover, immature target organ responsiveness to PTH may be present even in full-term neonates. We used the term "PTH insufficiency" because it was not easy to discriminate among the neonates who had absolute hypoparathyroidism, relative parathyroid deficiency, or transient target organ-unresponsiveness to PTH in one cross-sectional observation of serum calcium and intact PTH levels. Serial observations of them will give further information on causal relations.

Of 14 neonates who had 25OHD checked, 9 neonates had levels of $<10 \mathrm{ng} / \mathrm{mL}$. All of them showed relatively high phosphorus levels. Neonates with vitamin D deficiency had significantly lower serum calcium and higher phosphate concentrations compared to older infants with vitamin D deficiency (rickets) in a study in Indian neonates ${ }^{16)}$. Vitamin D crosses the placenta during gestation and establishes vitamin D stores for the newborn ${ }^{6}$. Because most of our neonates with $25 \mathrm{OHD}$ of $<10 \mathrm{ng} / \mathrm{mL}$ were formula feeding, low vitamin D levels in these neonates might mainly be due to low transfer of vitamin $\mathrm{D}$ from the mother during gestation. This finding supports that low maternal vitamin D levels are related to neonatal hypocalcemia. The intact PTH level was not increased considering the low serum calcium level in these neonates. In previous studies, low Mg levels have explained inappropriately low PTH levels in neonatal hypocalcemia, ${ }^{4,16)}$. However, in our study, the Mg level of most of the neonates was in the normal range. One possible explanation is that low maternal vitamin $\mathrm{D}$ leads to secondary hyperparathyroidism, which results in transient hypoparathyroidism and hypocalcemia in the neonate $^{16,17)}$

Hypocalcemic tetany is one of the serious symptoms of neo- 
natal hypocalcemia. In this study, 12 neonates showed abnormal EEGs, which were resolved in two months. Hypocalcemia is the cause of convulsion in approximately $3 \%$ of all cases in infants ${ }^{18}$. Not only muscle spasms and tetany but also seizures can present in moderate to severe hypocalcemia ${ }^{19)}$. Whereas tetany develops at the level of neuromuscular junctions, EEG abnormalities in hypocalcemia are considered to develop due to enhanced neuronal excitability of the central nervous system ${ }^{20)}$. Abnormal EEG findings associated with hypocalcemia include loss of alpha rhythm, many fast rhythms, and generalized spike-andwave discharge ${ }^{19)}$. The prognosis of simple hypocalcemic seizure is favorable. There was no recurrence of seizures, and epileptic form discharges disappeared from EEG after using antiepileptic medication for a short period and cessation ${ }^{21)}$.

Both tetany and QTc prolongation were observed across a wide range of serum calcium levels in our study. The average total calcium and iCa levels showing seizure-like activity were $6.4 \mathrm{mg} / \mathrm{dL}$ (range, $5.8-7.0 \mathrm{mg} / \mathrm{dL}$ ) and $2.7 \mathrm{mg} / \mathrm{dL}$ (range, 2.3-3.1 $\mathrm{mg} / \mathrm{dL}$ ), respectively, in a previous stud $\mathrm{y}^{20)}$ that showed similar results with our study. Whereas the traditional definition of neonatal hypocalcemia is a serum calcium level of less than 7.5$8.0 \mathrm{mg} / \mathrm{dL}^{21)}$, three neonates showed symptomatic hypocalcemia with calcium levels over $7.5 \mathrm{mg} / \mathrm{dL}$ in our study. Further studies on defining biologically low serum calcium levels are warranted.

This study has several limitations. Being a retrospective study, there was selection bias. Because of the small sample size and omitted blood parameters, we cannot fully present the factors associated with hypocalcemia. In particular, we are not able to explain the meaning of low vitamin D levels in TNH because serum vitamin $\mathrm{D}$ concentrations were checked in limited number of neonates. Nonetheless, this study is of value because we reviewed both symptomatic and asymptomatic hypocalcemic neonates and provided a specific description of the characteristics of hypocalcemia, and this provides valuable information to clinicians. Subsequently, it may assist to clarify the mechanisms of neonatal hypocalcemia.

In conclusion, formula-feeding predominance, PTH insufficiency and low serum vitamin D concentrations were observed in our neonates with hypocalcemia. Our findings support the hypothesis in which a low neonatal vitamin D reservoir and high phosphorus intake are associated with the development of PTH insufficiency, although the causal relationship is not clear in our study. In addition, symptoms such as tetany and QTc prolongation can develop in relatively mild hypocalcemia. Although the prognosis of hypocalcemic tetany is very favorable, TNH can cause transient EEG abnormalities.

\section{Conflict of interest}

No potential conflict of interest relevant to this article was reported.

\section{References}

1. Gertner JM. Disorders of calcium and phosphorus homeostasis. Pediatr Clin North Am 1990;37:1441-65.

2. Loughead JL, Mimouni F, Tsang RC. Serum ionized calcium concentrations in normal neonates. Am J Dis Child 1988;142:516-8.

3. Kovacs CS, Lanske B, Hunzelman JL, Guo J, Karaplis AC, Kronenberg HM. Parathyroid hormone-related peptide (PTHrP) regulates fetal-placental calcium transport through a receptor distinct from the $\mathrm{PTH} / \mathrm{PTHrP}$ receptor. Proc Natl Acad Sci U S A 1996;93:15233-8.

4. Thomas TC, Smith JM, White PC, Adhikari S. Transient neonatal hypocalcemia: presentation and outcomes. Pediatrics 2012;129:e1461-7.

5. Naylor KE, Iqbal P, Fledelius C, Fraser RB, Eastell R. The effect of pregnancy on bone density and bone turnover. J Bone Miner Res 2000;15:129-37.

6. Hsu SC, Levine MA. Perinatal calcium metabolism: physiology and pathophysiology. Semin Neonatol 2004;9:23-36.

7. Tsang RC, Chen IW, Friedman MA, Chen I. Neonatal parathyroid function: role of gestational age and postnatal age. J Pediatr 1973;83:728-38.

8. Kim HS. Calcium and phosphate metabolism and disorders in the newborn. Korean J Pediatr 2007;50:230-5.

9. Venkataraman PS, Tsang RC, Greer FR, Noguchi A, Laskarzewski P, Steichen JJ. Late infantile tetany and secondary hyperparathyroidism in infants fed humanized cow milk formula. Longitudinal follow-up. Am J Dis Child 1985;139:664-8.

10. Fomon SJ, Nelson SE. Calcium, phosphorus, magnesium, and sulfur. In: Fomon SJ. Nutrition of normal infants. St. Louis: Mosby-Year Book, 1993:192-216.

11. Abrams SA, Griffin IJ, Davila PM. Calcium and zinc absorption from lactose-containing and lactose-free infant formulas. Am J Clin Nutr 2002;76:442-6.

12. Ross AC, Taylor CL, Yaktine AL, Del Valle HB, editors; Committee to Review Dietary Reference Intakes for Vitamin D and Calcium; Institute of Medicine. Dietary reference intakes for calcium and vitamin D. Washington, DC: National Academies Press; 2011.

13. Abrams SA. Calcium absorption in infants and small children: methods of determination and recent findings. Nutrients 2010;2:474-80.

14. Standing Committee on the Scientific Evaluation of Dietary Reference Intakes; Food and Nutrition Board; Institute of Medicine. Dietary reference intakes for Calcium, Phosphorus, Magnesium, Vitamin D, and Fluoride. Washington, DC: National Academies Press; 1997.

15. Okonofua F, Menon RK, Houlder S, Thomas M, Robinson D, O'Brien S, et al. Parathyroid hormone and neonatal calcium homeostasis: evidence for secondary hyperparathyroidism in the Asian neonate. Metabolism 1986;35:803-6.

16. Newman DB, Fidahussein SS, Kashiwagi DT, Kennel KA, 
Kashani KB, Wang Z, et al. Reversible cardiac dysfunction associated with hypocalcemia: a systematic review and meta-analysis of individual patient data. Heart Fail Rev 2014;19:199-205.

17. Nekvasil R, Stejskal J, Tuma A. Detection of early onset neonatal hypocalcaemia in low birth weight infants by Q-Tc and Q-oTc interval measurement. Acta Paediatr Acad Sci Hung 1980;21:203-10.

18. Lynch BJ, Rust RS. Natural history and outcome of neonatal hypocalcemic and hypomagnesemic seizures. Pediatr Neurol 1994;11:23-7.

19. Sankar JM, Agarwal R, Deorari A, Paul VK. Management of neonatal seizures. Indian J Pediatr 2010;77:1129-35.

20. Song JY, Shin YL, Yoo HW. Clinical characteristics of symptomatic hypocalcemic infants. J Korean Soc Pediatr Endocrinol 2002;7:95-104.

21. Sperling MA. Pediatric endocrinology. 4th ed. Philadelphia: WB Saunders Co., 2014:734. 